\title{
Absorption coefficient of urban aerosol in Nanjing, west Yangtze River Delta, China
}

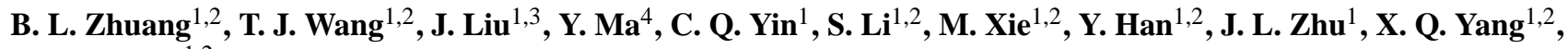 \\ and C. B. Fu ${ }^{1,2}$ \\ ${ }^{1}$ School of Atmospheric Sciences, Nanjing University, Xianlin Ave. 163, Nanjing 210023, China \\ ${ }^{2}$ Collaborative Innovation Center of Climate Change, Jiangsu, China \\ ${ }^{3}$ Department of Geography and Planning, University of Toronto, Toronto, M5S 3G3, Canada \\ ${ }^{4}$ School of Environmental Science and Engineering, Nanjing University of Information Science and Technology, \\ Ningliu Rd. 219, Nanjing 210044, China
}

Correspondence to: B. L. Zhuang (blzhuang@nju.edu.cn)

Received: 29 April 2015 - Published in Atmos. Chem. Phys. Discuss.: 16 June 2015

Revised: 4 November 2015 - Accepted: 24 November 2015 - Published: 10 December 2015

\begin{abstract}
Absorbing aerosols can significantly modulate short-wave solar radiation in the atmosphere, affecting regional and global climate. The aerosol absorption coefficient (AAC) is an indicator that assesses the impact of absorbing aerosols on radiative forcing. In this study, the near-surface AAC and absorption Ångström exponent (AAE) in the urban area of Nanjing, China, are characterized on the basis of measurements in 2012 and 2013 using the seven-channel Aethalometer (model AE-31, Magee Scientific, USA). The AAC is estimated with direct and indirect corrections, which result in consistent temporal variations and magnitudes of $\mathrm{AAC}$ at $532 \mathrm{~nm}$. The mean AAC at $532 \mathrm{~nm}$ is about $43.23 \pm$ $28.13 \mathrm{M} \mathrm{m}^{-1}$ in the urban area of Nanjing, which is much lower than that in Pearl River Delta and the same as in rural areas (Lin'an) in Yangtze River Delta. The AAC in the urban area of Nanjing shows strong seasonality (diurnal variations); it is high in cold seasons (at rush hour) and low in summer (in the afternoon). It also shows synoptic and quasi-2-week cycles in response to weather systems. Its frequency distribution follows a typical log-normal pattern. The $532 \mathrm{~nm}$ AAC ranging from 15 to $65 \mathrm{M} \mathrm{m}^{-1}$ dominates, accounting for more than $72 \%$ of the total data samples in the entire study period. Frequent high pollution episodes, such as those observed in June 2012 and in winter 2013, greatly enhanced AAC and altered its temporal variations and frequency distributions. These episodes are mostly due to local emissions and regional pollution. Air masses flowing from northern China to Nanjing can sometimes be highly pol-
\end{abstract}

luted and lead to high AAC at the site. AAE at 660/470 nm from the Schmid correction (Schmid et al., 2006) is about 1.56, which might be more reasonable than from the Weingartner correction (Weingartner et al., 2003). Low AAEs mainly occur in summer, likely due to high relative humidity $(\mathrm{RH})$ in the season. AAC increases with increasing AAE at a fixed aerosol loading. The $\mathrm{RH}-\mathrm{AAC}$ relationship is more complex. Overall, AAC peaks at RH values of around $40 \%$ $(1.3<\mathrm{AAE}<1.6), 65 \%(\mathrm{AAE}<1.3$ and $\mathrm{AAE}>1.6)$, and $80 \%(1.3<\mathrm{AAE}<1.6)$.

\section{Introduction}

Atmospheric aerosols, their loadings having increased in recent years, can significantly influence regional or global climate because of their direct and indirect interactions with short-wave solar radiation in the atmosphere (Forster et al., 2007). Absorbing aerosols, which are mostly composed of dust in desert areas and of black carbon (BC) in regions with frequent human activities, can strongly absorb solar radiation, resulting in changes in atmospheric circulations and the hydrological cycle. Although the warming effect of $\mathrm{CO}_{2}$ could be greatly offset by the scattering aerosol direct effect in the regions with high aerosol concentrations (Kiehl and Briegleb, 1993), it might be further strengthened by BC aerosols because the warming effect of $\mathrm{BC}$ aerosols on the global scale is significant, only surpassed by $\mathrm{CO}_{2}$ (Jacobson, 
2002). Menon et al. (2002) suggested that the trend of precipitation in China over the past decades, with increased rainfall in the south and drought in the north, might be related to the variation of $\mathrm{BC}$ in the region.

Previous studies have focused on the aerosol optical properties, radiative forcing, and climate effects on both global and regional scales, using model simulations (Penner et al., 2001; Liao and Seinfeld, 2005; Zhuang et al., 2013a, b) and satellite/ground-based observations (Bellouin et al., 2003; Yan et al., 2008; Wu et al., 2012; Zhuang et al., 2014a; etc.) in the past 20 years. Forster et al. (2007) simulated the global mean direct radiative forcing of total aerosols and $\mathrm{BC}$, which ranges between +0.04 and $-0.63 \mathrm{~W} \mathrm{~m}^{-2}$ and between +0.1 and $+0.3 \mathrm{Wm}^{-2}$, respectively. Over east Asia, the simulated $\mathrm{BC}$ direct radiative forcing varies from +0.32 to $+0.81 \mathrm{~W} \mathrm{~m}^{-2}$ (Zhuang et al., 2013a). All of the above showed significant uncertainties in estimating the aerosol direct radiative forcing in numerical models. These uncertainties are mostly due to the uncertainties in the aerosol optical properties (Holler et al., 2003) which are related to the aerosol emissions, profiles, compositions, and mixing states. Forster et al. (2007) stated that the uncertainties could be reduced if observed aerosol optical properties were employed when estimating the forcing. China has experienced rapid population and economic growth during the past 3 decades, resulting in enhanced aerosol and trace gas emissions. Streets et al. (2001) suggested that the BC emissions in China roughly account for one-quarter of the global anthropogenic emissions, although the uncertainty of this estimate is large. The BC aerosols are mostly emitted in southwest and north China, in the regions of Yangtze River Delta (YRD) and Pearl River Delta (PRD)(Zhang et al., 2009). Recently, many observation-based studies have been conducted on the aerosol optical properties and direct radiative forcing over China (Xu et al., 2004; Yan, 2006; Xia et al., 2007; Yan et al., 2008; He et al., 2009; Wang et al., 2009; Wu et al., 2009; Li et al., 2010; Cai et al., 2011; Bai et al., 2011; Xiao et al., 2011; Zhou et al., 2011; Wu et al., 2012; etc.). Some of them focused on the total extinction or optical depth of the aerosols. Xia et al. (2007) reported that the annual mean aerosol optical depth (AOD) at $500 \mathrm{~nm}$ and the Ångström exponent (AE) of total aerosols in YRD were 0.77 and 1.17, respectively. Xiao et al. (2011) analyzed the temporal and spatial variations of the total aerosol optical depth and Ångström exponent using CE-318 in Hangzhou. Zhuang et al. (2014a) suggested that column AOD and absorption AE (AAE) of absorbing aerosols were $0.04 \pm 0.02$ and $1.44 \pm 0.50$ in the urban area of Nanjing. The aerosol absorption coefficients (AACs) were also studied for several urban and rural areas of China. The AAC at $565 \mathrm{~nm}$ in the Gobi Desert was found to be as low as $6 \pm 11 \mathrm{Mm}^{-1}$ (Yulin) (Xu et al., 2004). The annual $532 \mathrm{~nm} \mathrm{AAC}$ was about $17.54 \pm 13.44 \mathrm{Mm}^{-1}$ at a rural site, while it was about $45 \pm 39 \mathrm{Mm}^{-1}$ at an urban site, in Beijing (Yan et al., 2008; He et al., 2009). The AAC at $532 \mathrm{~nm}$ was as large as $82 \pm 23 \mathrm{Mm}^{-1}$ in the urban area of Pearl River Delta (PRD) in south China (Wu et al., 2009).

Although considerable research on this issue has been conducted, there are still insufficient studies on a regional scale in China, especially on the AAC in YRD, one of the fastestgrowing regions in China. To fill the gaps in research, this study characterizes the AAC in YRD using the near-surface absorption coefficient and Ångström exponent of absorbing aerosols in the urban area of Nanjing, a typical developing city in west Yangtze River Delta, China. In the following, the method is described in Sect. 2, results and discussions are presented in Sect. 3, followed by conclusions in Sect. 4.

\section{Methodologies}

\subsection{Sampling station and instruments}

The sampling site is located in the Gulou campus of Nanjing University, the urban area of Nanjing $\left(32.05^{\circ} \mathrm{N}, 118.78^{\circ} \mathrm{E}\right)$. It is built on the roof of a $79.3 \mathrm{~m}$ tall building, around which there are no industrial pollution sources within a $30 \mathrm{~km} \mathrm{ra-}$ dius but there are several main roads with evident traffic pollution. The sketch map of the site (not shown) is the same as Fig. 1 of Zhu et al. (2012). The black carbon aerosol mass concentration and aerosol absorption coefficient were derived from the measurements using the 7-channel Aethalometer (model AE-31, Magee Scientific, USA). The AE-31 model measures light attenuation at seven wavelengths $(370,470,520,590,660,880$, and $950 \mathrm{~nm}$, respectively). The aerosol inlet is located $\sim 1 \mathrm{~m}$ above the roof. Routine flow calibration and blank tests were performed before sampling. Details on the AE-31 and its sampling principles can be referred to Hansen et al. (1984), Weingartner et al. (2003) and Arnott et al. (2005). Near-real-time continuous measurements were made at the site since 1 January 2012, using the AE-31, with a desired flow rate of $5.0 \mathrm{~L} \mathrm{~min}^{-1}$ and a sampling interval of $5 \mathrm{~min}$. Two years of data, from 2012 and 2013, are used in this study. Meteorological data are from the National Meteorological Station of Nanjing (no. 58238).

\subsection{Calculation of AE-31_absorption coefficient}

The absorption coefficient is defined by Beer-Lambert's law as shown in Eq. (1) in Weingartner et al. (2003) and Arnott et al. (2005), which is associated with the intensities of the incoming light and remaining light after passing through a medium. A variable attenuation (ATN), which is given as a percentage value, is defined to represent filter attenuation through the sample spot in the tape (Eq. 2 in Weingartner et al., 2003, and Arnott et al., 2005) inside the instrument. Aerosol light absorption coefficient and $\mathrm{BC}$ mass concentration can be calculated directly based on the measured light attenuation through a quartz filter matrix. There are two ways of calculating aerosol light absorption coefficient. The indirect calculation (IDC for short), which is much simpler than 
the direct ones, is expressed in Eq. (1):

$\sigma_{\mathrm{abs}, t}(\lambda)=[\mathrm{BC}] \times \gamma$,

where $[\mathrm{BC}]$ is the mass concentration of Aethalometer BC (in $\mu \mathrm{g} \mathrm{m}^{3}$ ) without any correction and $\gamma$ is the conversion factor determined empirically from linear regression of the Aethalometer BC concentration versus the aerosol absorption measurement (Yan et al., 2008). Wu et al. (2009) indicated that the conversion factor $\gamma$ from the linear regression of the Aethalometer BC concentrations $\left(\mathrm{ng} \mathrm{m}^{-3}\right)$ at $880 \mathrm{~nm}$ against the light absorption coefficient $\left(\mathrm{Mm}^{-1}\right)$ at $532 \mathrm{~nm}$ in south China was about $8.28 \mathrm{~m}^{2} \mathrm{~g}^{-1} \cdot \gamma=11.05 \mathrm{~m}^{2} \mathrm{~g}^{-1}$ in the suburb of Nanjing.

In addition to the indirect way, the wavelength-dependent aerosol absorption coefficient can be calculated directly based on the measured light attenuation (ATN) at seven wavelengths $(370,440,520,590,660,880$, and $950 \mathrm{~nm})$ as shown in Eq. (2):

$\sigma_{\mathrm{ATN}, t}(\lambda)=\frac{\left(\operatorname{ATN}_{t}(\lambda)-\operatorname{ATN}_{t-1}(\lambda)\right)}{\Delta t} \times \frac{A}{V}$,

where $A\left(\right.$ in $^{2}$ ) is the area of the aerosol-laden filter spot, $V$ is the volumetric sampling flow rate (in $\mathrm{L} \mathrm{min}^{-1}$ ), and $\Delta t$ is the time interval (i.e., $5 \mathrm{~min}$ ) between $t$ and $t-1$. It is well known that $\sigma_{\mathrm{ATN}}$ is generally larger than the actual aerosol absorption coefficient $\sigma_{\mathrm{abs}}$ because of the optical interactions of the filter substrate with the deposited aerosol (Petzold et al., 1997; Weingartner et al., 2003; Arnott et al., 2005; Schmid et al., 2006). The key factors leading to the bias include (1) multiple-scattering of light at the filter fibers (multiple-scattering effect), which may result in the overestimation of the $\sigma$, and (2) the instrumental response with increased particle loading on the filter (shadowing effect), which may lead to underestimation of the $\sigma$. Therefore, the calibration factors $C$ and $R$ (shown in Eq. 3) are introduced to address the scattering effect and shadowing effect, respectively:

$\sigma_{\mathrm{abs}, t}(\lambda)=\frac{\sigma_{\mathrm{ATN}, t}(\lambda)}{C \times R}$.

To address the uncertainties, several correction algorithms, including Weingartner (Weingartner et al., 2003), Arnott (Arnott et al., 2005), Schmid (Schmid et al., 2006), Virkkula (Virkkula et al., 2007) corrections, have been developed. Collaud Coen et al. (2010) suggested that both Weingartnercorrected (WC2003 for short, hereinafter) and Schmidcorrected (SC2006 for short, hereinafter) absorptions show good agreements with the one from the Multi-Angle Absorption Photometer. Therefore, these two corrections, which have a similar formula, shown in Eq. (4), are applied in this study to investigate the absorption coefficient:

$\sigma_{\mathrm{abs}, t}(\lambda)=\frac{\sigma_{\mathrm{ATN}, t}(\lambda)}{C \times\left(\left(\frac{1}{f}-1\right) \times \frac{\ln \left(\mathrm{ATN}_{t}(\lambda)\right)-\ln 10}{\ln 50-\ln 10}+1\right)}$.
Both of them have the same $R(\lambda)$ :

$R_{\mathrm{t}}(\lambda)=\left(\frac{1}{f}-1\right) \times \frac{\ln \left(\operatorname{ATN}_{\mathrm{t}}(\lambda)\right)-\ln 10}{\ln 50-\ln 10}+1$,

where $R=1$ when $\mathrm{ATN} \leq 10 . f$ can be calculated according to Weingartner et al. (2003):

$f(\lambda)=n \times(1-\omega(\lambda))+1$,

where $\omega$ is the wavelength-dependent single-scattering albedo (SSA) and $n$ is a constant $(=0.86 \pm 0.01)$. Note that the reliability of the $n$ value $(0.86)$ is limited because this value is mostly estimated under the condition of $\omega<0.6$, which may result in a large bias. Therefore, an empirical $f=1.2$ (when $\omega \simeq 0.9$ ), which is independent of wavelength as suggested by Schmid et al. (2006), is used for both WC2003 and SC2006 in this study.

The multiple-scattering correction in WC2003 is also different from that in SC2006. Weingartner (Weingartner et al., 2003 ) indicated that the two-waveband ( 450 and $660 \mathrm{~nm}$ ) averaged $C$ was about 3.6 for non-fresh soot. In this study, $C$ in WC2003 is independent of wavelength and is set to 3.48 for China according to Wu et al. (2013). In contrast, Schmid (Schmid et al., 2006) pointed out that $C$, which is wavelength-dependent, is initially expressed as follows:

$C(\lambda)=C^{*}(\lambda)+m_{\mathrm{s}}(\lambda) \times \frac{\omega(\lambda)}{1-\omega(\lambda)}$,

where $m_{\mathrm{S}}$ represents the fraction of the aerosol-scattering coefficient and $\omega$ is SSA. Optical properties from CE-318 were used in this study because there were no concomitant scattering measurements at the site during the whole sampling period. Thus, we assumed that the SSA and AAE at the low layers of atmosphere were equated to the column ones. According to Zhuang et al. (2014a), annual mean $\omega(440)=0.922$, $\omega(675)=0.924$, and $\alpha_{\mathrm{a}, 675 / 440 \mathrm{~nm}}=1.44$ at the site. Based on $\alpha_{\mathrm{a}, 675 / 440 \mathrm{~nm}}$ and according to the definition:

$\omega(\lambda)=\frac{\sigma_{\mathrm{s}}(\lambda)}{\sigma_{\mathrm{s}}(\lambda)+\sigma_{\mathrm{a}}(\lambda)}$,

$\alpha_{\mathrm{s}, 675 / 440 \mathrm{~nm}}$ can be calculated as follows (Ångström, 1929):

$$
\begin{aligned}
\alpha_{\mathrm{s}, 675 / 440 \mathrm{~nm}} & =-\frac{\log \left(\frac{\sigma_{\mathrm{s}}(675)}{\sigma_{\mathrm{s}}(440)}\right)}{\log (675 / 440)} \\
& =-\frac{\log \left(\frac{1-\omega(440)}{\omega(440)} \times \frac{\omega(675)}{1-\omega(675)}\right)}{\log (675 / 440)}+\alpha_{\mathrm{a}, 675 / 440 \mathrm{~nm}} .
\end{aligned}
$$

Thus, $\alpha_{\mathrm{s}, 675 / 440 \mathrm{~nm}}=1.51$.

All wavelength-dependent SSAs could be calculated based on the following formula (Schmid et al., 2006):

$\omega(\lambda)=\frac{\omega_{0} \times\left(\frac{\lambda}{\lambda_{0}}\right)^{-\alpha_{\mathrm{s}}}}{\omega_{0} \times\left(\frac{\lambda}{\lambda_{0}}\right)^{-\alpha_{\mathrm{s}}}+\left(1-\omega_{0}\right) \times\left(\frac{\lambda}{\lambda_{0}}\right)^{-\alpha_{\mathrm{a}}} .}$ 


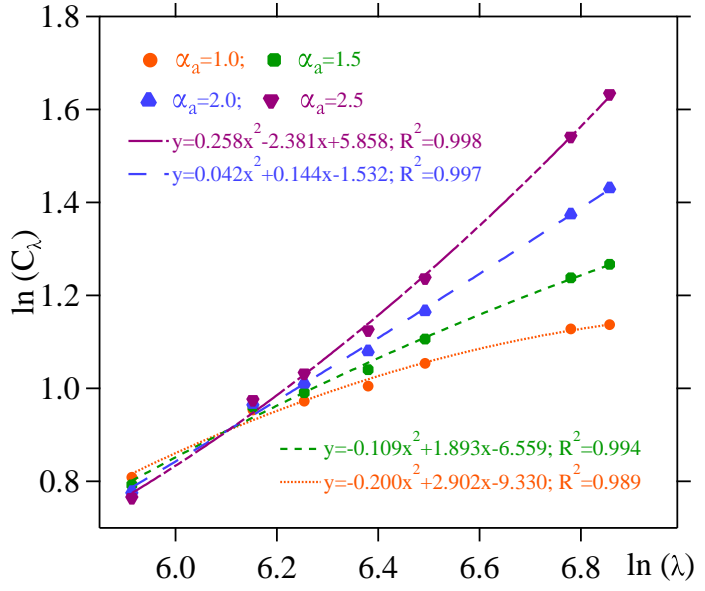

Figure 1. Double logarithmic plot of $C$ versus $\lambda$ for $\alpha_{\mathrm{a}}=1$ (orange), 1.5 (green), 2 (blue), and 2.5 (violet), respectively.

Here, $\omega_{0}, \lambda_{0}$, and $\alpha_{\mathrm{s}, 675 / 440}$ were set to $0.922,440 \mathrm{~nm}$, and 1.51 , respectively. Based on the given $C^{*}(\lambda)$ and $m_{\mathrm{s}}(\lambda)$ in Table 1 of Arnott et al. (2005), $C(\lambda)$ of pure candle light soot was estimated. To parameterize the dependence among $C(\lambda)$, $\lambda$ and $\alpha_{\mathrm{a}}, \ln (C)$ versus $\ln (\lambda)$ for $\alpha_{\mathrm{a}}=1,1.5,2$, and 2.5 were plotted in Fig. 1, and a quadratic fit (universal formula as shown in Eq. 11) for each $\alpha_{\mathrm{a}}$ value was established following Schmid (Schmid et al., 2006) who suggested that the fits in Fig. 1 were applicable to other kind of soot, based on given $\omega$ and $\alpha_{\mathrm{s}}$.

$\ln (C(\lambda))=A \times \ln (\lambda)^{2}+B \times \ln (\lambda)+D$

Equation (11) can be transformed into

$C(\lambda)=C_{\mathrm{ref}} \times \frac{\lambda^{A \times \ln (\lambda)+B}}{\lambda_{\mathrm{ref}}^{A \times \ln (\lambda)+B}}$.

$\alpha_{\mathrm{a}}$-dependent $A$ and $B$ are shown in the quadratic equations of Fig. 1. $A$ and $B$ versus $\alpha_{\mathrm{a}}$ are shown in Fig. 2 and a quadratic fit is made based on the given $\omega$ and $\alpha_{\mathrm{s}}$ at our site for $A$ and $B$ individually shown as Eqs. (13) and (14).

$A=0.123 \times \alpha_{\mathrm{a}}^{2}-0.128 \times \alpha_{\mathrm{a}}-0.195$

$B=-1.512 \times \alpha_{\mathrm{a}}^{2}+1.774 \times \alpha_{\mathrm{a}}+2.637$

Based on Eqs. (12), (13), and (14), $C(\lambda)$ at our site could be estimated for a given $\alpha_{\mathrm{a}}$ and $C_{\text {ref. }}$. Schmid et al. (2006) indicated that $C_{\text {ref }}$ at $532 \mathrm{~nm}$ is about 2.1 and 4.0 for pure or external mixtures of soot and internal mixtures of soot, respectively. For the urban aerosols, the mean value 3.6 (Schmid et al., 2006) was suggested and used in this study. Thus $C$ was $2.95,3.37,3.56,3.79,3.99,4.51$, and 4.64 at $370,470,520$, $590,660,880$, and $950 \mathrm{~nm}$, respectively.

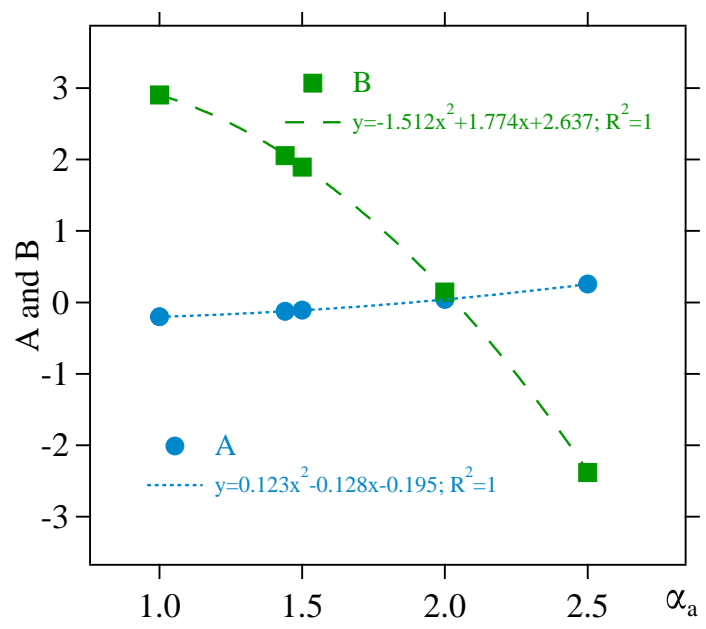

Figure 2. Variations of the coefficients $A$ and $B$ with $\alpha_{\mathrm{a}}$.

As indicated in Collaud Coen et al. (2010), it is not recommended to use Virkkula correction and Arnott correction to correct the absorption coefficient because the Virkkula correction does not consider all the known artifacts and the Arnott correction has technical limits due to the generation of new negative absorption coefficient values. Although the determination of the $f$ constant used in the WC2003 is not clearly defined, it still shows a very good agreement with the Multi-Angle Absorption Photometer. Similar to Arnott correction, SC2006 also introduces artifacts in the absorption wavelength dependence, but to a lesser extent. And it also shows a very good agreement with the Multi-Angle Absorption Photometer (Collaud Coen et al., 2010). Therefore, to estimate the absorption coefficient of the aerosol in the urban area of Nanjing, both direct and indirect ways introduced above were employed in this study although the indirect way could only address $\sigma_{\mathrm{abs}}$ at $532 \mathrm{~nm}$. To make the comparison, $532 \mathrm{~nm} \sigma_{\mathrm{abs}}$ from WC2003 and SC2006 was derived using the 520 and $590 \mathrm{~nm} \sigma_{\mathrm{abs}}$ according to the following equations (Ångström, 1929):

$\alpha_{\mathrm{abs}, 590 / 520 \mathrm{~nm}}=-\frac{\log \left(\sigma_{\mathrm{abs}, 590 \mathrm{~nm}} / \sigma_{\mathrm{abs}, 520 \mathrm{~nm}}\right)}{\log \left(590_{\mathrm{nm}} / 520_{\mathrm{nm}}\right)}$

$\sigma_{\mathrm{abs}, 532 \mathrm{~nm}}=\sigma_{\mathrm{abs}, 520 \mathrm{~nm}} \times\left(\frac{532_{\mathrm{nm}}}{520_{\mathrm{nm}}}\right)^{-\alpha_{\mathrm{abs}, 590 / 520 \mathrm{~nm}}}$.

\section{Results and discussion}

\subsection{Temporal variations of the aerosol absorption coefficient}

We corrected the AAC in the urban area of Nanjing during the period from 2012 to 2013, using three methods: IDC, 


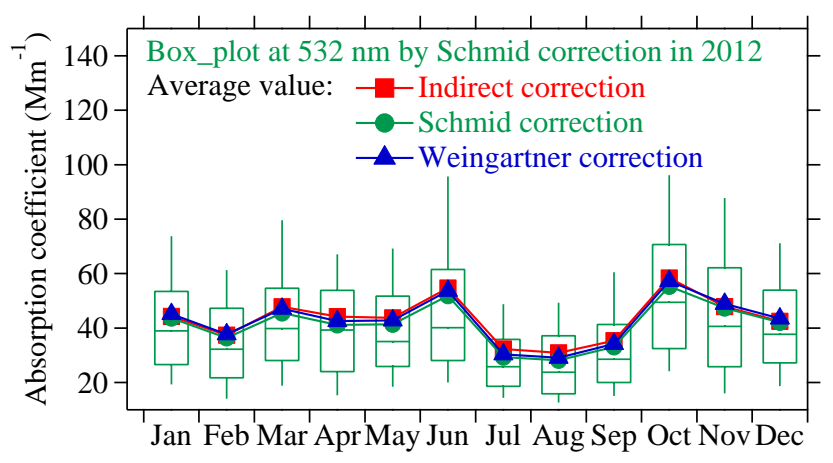

(a)

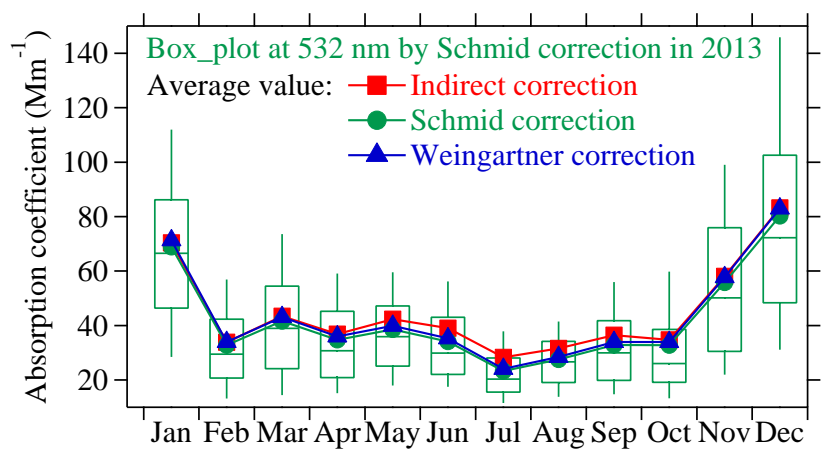

(b)

Figure 3. Monthly variations of the aerosol absorption coefficients $\left(\mathrm{Mm}^{-1}\right)$ at $532 \mathrm{~nm}$ in the urban area of Nanjing in 2012 (a) and 2013 (b). The 10th, 25th, median, 75th, and 90th percentile values of the coefficient corrected by SC2006 are presented as box plots. The monthly means of the coefficients corrected by IDC (red), WC2003 (blue), and SC2006 (light green), are presented as line markers.

WC2003, and SC2006. It is worth noting that the indirect correction could only estimate a single-wavelength AAC (at $532 \mathrm{~nm}$ ). To make the corrections comparable, $532 \mathrm{~nm}$ AACs from WC2003 and SC2006 were calculated by Eqs. (15) and (16). Temporal variations of AACs for the rest of wavelengths from WC2003 and SC2006 corrections are similar to those of $532 \mathrm{~nm}$ AAC (not shown).

Figure 3 presents the monthly variations of $532 \mathrm{~nm} \mathrm{AAC}$ in the urban area of Nanjing in 2012 (Fig. 3a) and 2013 (Fig. 3b) corrected by IDC, WC2003, and SC2006. The seasonal variations and the magnitude of the AAC at $532 \mathrm{~nm}$ agree closely between the direct and indirect corrections. The relatively large difference in AACs between the direct and indirect corrections was in spring and summer (wet seasons) both in 2012 and 2013. The difference is mostly caused by the shadowing effect $R$ because [BC] directly from AE31 in Eq. (1) has not been corrected. The bias of the actual $\mathrm{BC}$ concentration from $[\mathrm{BC}]$ is from the $R$ as suggested by Eq. (7) in Schmid et al. (2006) and Eq. (7) in Weingartner et al. (2003). Thus, the results imply the importance of the shadowing effect in estimating AACs. The 2-year mean AAC at $532 \mathrm{~nm}$ averaged from the three corrections is about $43.23 \pm 28.13 \mathrm{Mm}^{-1}$, with a maximum and a minimum of 273 and $1.28 \mathrm{Mm}^{-1}$, respectively. The AAC at $532 \mathrm{~nm}$ corrected by IDC is the largest $\left(44.38 \mathrm{Mm}^{-1}\right)$, followed by that corrected by WC2003 $\left(43.38 \mathrm{Mm}^{-1}\right)$ and SC2006 $\left(41.93 \mathrm{M} \mathrm{m}^{-1}\right)$. AACs in 2012 were a little smaller than those in 2013. The AAC in the urban area of Nanjing had an evident seasonal variation in both 2012 and 2013; it was generally high in cold seasons and mostly low in warm seasons. Both precipitation and BC emissions may somewhat influence the seasonal variations in the AAC. In summer, high frequent precipitation and low $\mathrm{BC}$ emissions (Zhang et al., 2009) result in low BC concentrations, which is opposite to those in winter as suggested by Zhuang et al. (2014b). Additionally, serious pollution episodes would lead to high levels of BC loadings, thus considerably enhancing AACs. Although AACs are generally expected to be small in summer due to low BC concentrations, the AAC was substantially large in June 2012 (Fig. 3a). The monthly mean AAC in this month from SC2006 is $51.89 \mathrm{M} \mathrm{m}^{-1}$, which is about $1.5,1.4$, and 1.8 times that in June 2012, in the summer of 2012 and the summer of 2013, respectively. Such high AAC values mainly result from a seriously polluted $\mathrm{BC}$ event during the period from 1 to 15 June 2012. High BC loadings during this period were due to a high intensity of biomass burning in the northwestern region of Nanjing (Zhuang et al., 2014b). Figure 3 shows that the monthly variation of the AAC in 2012 was different from that in 2013. The highest AACs were in June and October 2012 while in 2013, the AAC was at a maximum in winter (January, November, and December). The large differences between the 2 years may be due to the difference in pollution episodes, which eventually results in different seasonal variations of AACs in Fig. 3.

The AAC also shows substantial diurnal variation (Fig. 4). It was high at rush hour (around 07:00-09:00 and 19:00 21:00) but low in the afternoon (around 13:00-15:00) almost in all seasons in the urban area of Nanjing in 2012 and 2013. At 07:00, mean $532 \mathrm{~nm} \mathrm{AAC} \mathrm{was} \mathrm{as} \mathrm{large} \mathrm{as} \mathrm{about}$ $50 \mathrm{M} \mathrm{m}^{-1}$, while at $14: 00$, it was about $33 \mathrm{Mm}^{-1}$. The large AACs during the periods of a day might be caused by the vehicle emissions (because the site is surround by several main roads with apparent traffic pollution, as mentioned in Sect. 2) while the small AAC in the afternoon is induced by a well-developed boundary layer (Zhuang et al., 2014b). Because the diurnal variations of the AAC at $532 \mathrm{~nm}$ from IDC, WC2003, and SC2006 are similar (Fig. 4a), one of them (SC2006) was selected to characterize the diurnal variation of the AAC in detail (Fig. 4b). The diurnal variation of AAC shows much stronger seasonality in 2013 than that in 2012 (Fig. 4b), which might be caused by the substantial pollution episodes discussed above. In 2012, highly intensified biomass burning in early June near Nanjing resulted in higher BC concentrations (Zhuang et al., 2014b) and thus a larger AAC than those in 2013. An extremely high AAC in the winter of 2013 might also result from the poor air quality 


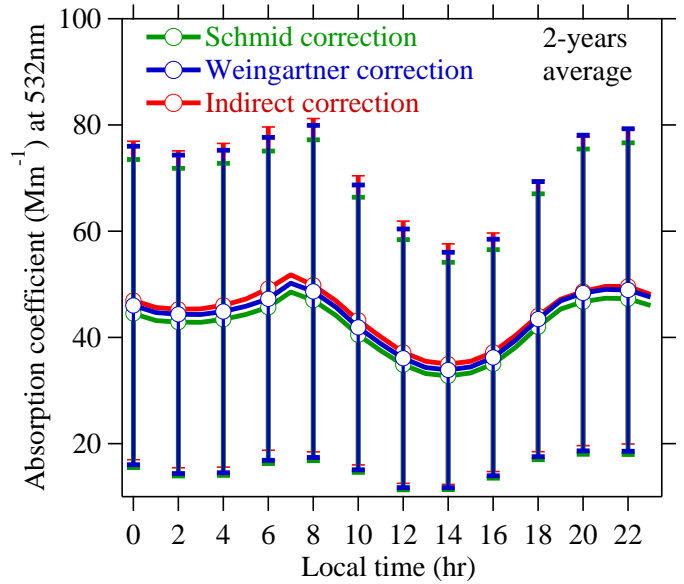

(a)

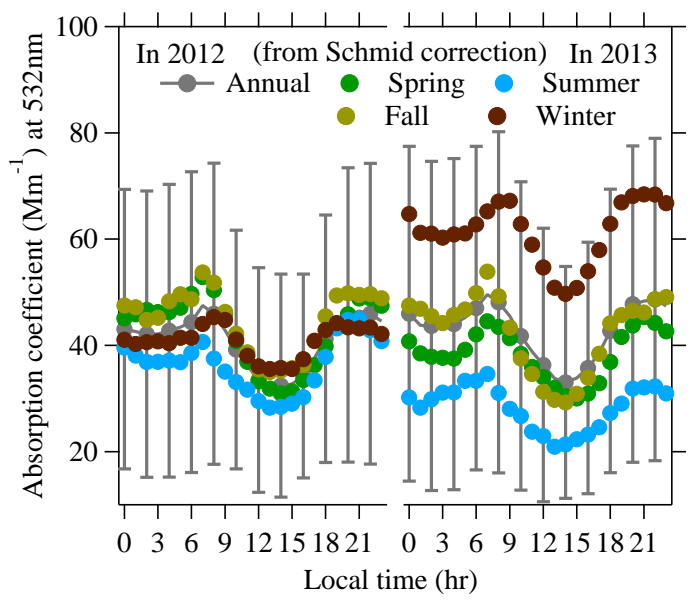

(b)

Figure 4. Diurnal variations of the aerosol absorption coefficients at $532 \mathrm{~nm}$ in the urban area of Nanjing. Panel (a) shows the 2-year (2012-2013) coefficients corrected by IDC (red), WC2003 (blue), and SC2006 (light green); and (b) shows the coefficients corrected by SC2006 in separate seasons of 2012 and 2013. March, April, and May represent the spring; June, July, and August represent the summer; September, October, and November represent the fall; and January, February, and December in 2012 (2013) represent the winter in 2012 (2013).

during the period. The diurnal cycle could also deviate from its normal pattern (peak at rush hours and trough in afternoon). Figure $4 \mathrm{~b}$ also shows that the standard deviations of the AAC in $2012\left(25.12 \mathrm{Mm}^{-1}\right)$ are smaller than those in $2013\left(28.58 \mathrm{M} \mathrm{m}^{-1}\right)$ although their means in 2012 and 2013 are close to each other.

\subsection{Frequencies of the aerosol absorption coefficient}

Similar to the seasonal variation, the frequency patterns of AACs for the rest of wavelengths are consistent with those of $532 \mathrm{~nm}$ AAC, so the following discussion is focused on the

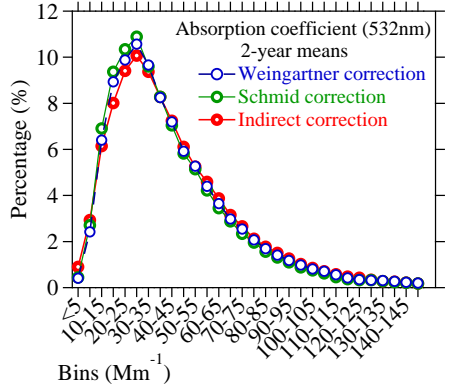

(a)

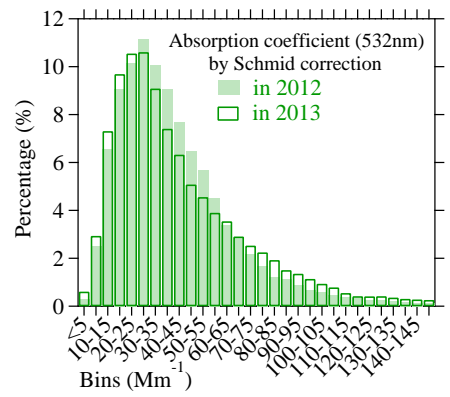

(b)

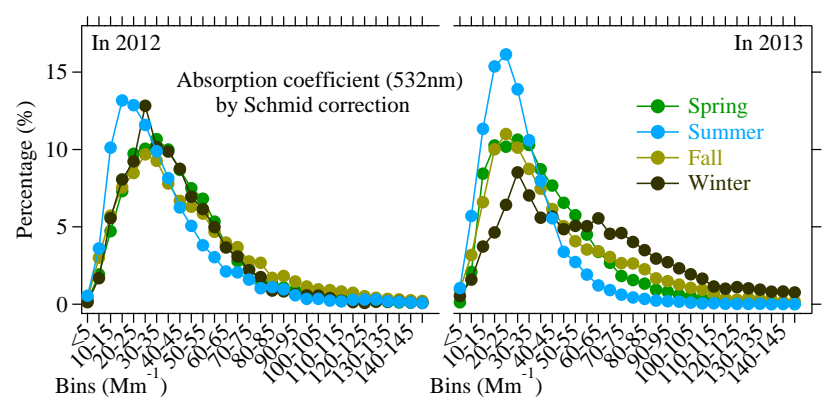

(c)

Figure 5. Frequency distributions of the aerosol absorption coefficients at $532 \mathrm{~nm}$ in the urban area of Nanjing. (a) the 2-year (20122013) coefficients corrected by IDC (red), WC2003 (blue), and SC2006 (light green). Panel (b) shows the coefficients corrected by SC2006 in the separate years of 2012 (solid bar) and 2013 (blank bar), and panel (c) shows the coefficients corrected by SC2006 in separate seasons of separate years.

frequency of $532 \mathrm{~nm}$ AAC only to avoid duplication. Figure $5 \mathrm{a}$ shows the frequency distributions of $532 \mathrm{~nm}$ AAC corrected by IDC, WC2003, and SC2006 during the study period, following a typical log-normal pattern. The range from 15 to $65 \mathrm{Mm}^{-1}$ dominated, accounting for more than $72 \%$ of the total data samples during the period. The maximum frequencies of $10.07 \%$ (IDC), $10.57 \%$ (WC2003), and $10.89 \%$ (SC2006) occurred in the ranges from 25 to $30 \mathrm{M} \mathrm{m}^{-1}$. The absolute differences between the directly and indirectly corrected AACs were relatively larger in the range from 20 to $25 \mathrm{M} \mathrm{m}^{-1}$ than those in other ranges, possibly due to the influence of the shadowing effect in warming seasons as analyzed in Sect. 3.1. Because of the consistencies 
(a) wavelet power spectrum with $5 \%$ sig

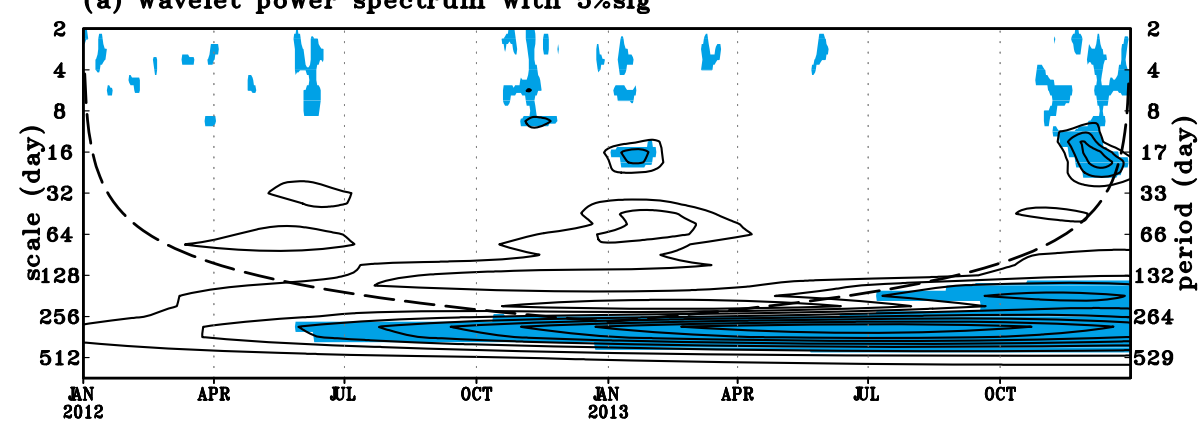

(b) wavelet real part spectrum

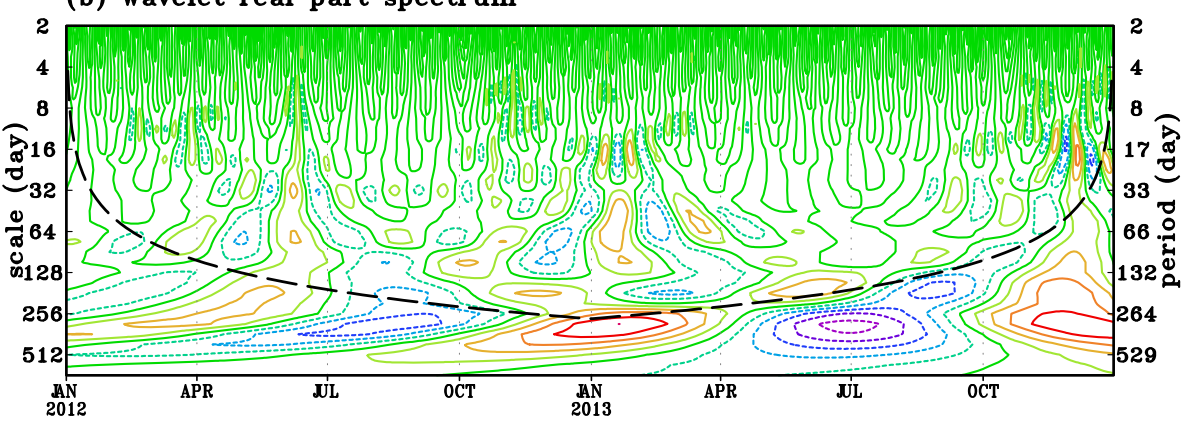

Figure 6. The local wavelet power spectrum (a) and wavelet real part spectrum (b) of the aerosol absorption coefficient at $532 \mathrm{~nm}$ using the Morlet wavelet. The left axis is the wavelet scale (in day) corresponding to the Fourier period on the right axis. The bottom axis is local time (month). The filled parts in panel (a) indicate passing the $95 \%$ confidence level test, and the parts below the dashed line signify unlikelihood.

in the frequency patterns and magnitudes among the three AACs, only the frequency of SC2006 AAC at $532 \mathrm{~nm}$ is presented in detail to illustrate the interannual and seasonal variations of the frequency (Fig. $5 \mathrm{~b}$ and c). Similar to the diurnal cycle, frequency distributions of the AAC in 2012 are more consistent with each other and more concentrated than those in 2013. Frequencies in the ranges below $25 \mathrm{Mm}^{-1}$ $(28.57 \%)$ and above $70 \mathrm{Mm}^{-1}(10.62 \%)$ are smaller in 2012 compared to 2013 (31.09 and $15.47 \%$, respectively). The peak frequency mostly occurs in the smaller AAC range in summer while in the larger ones in other seasons. Additionally, pollution episodes might alter the shape of the frequencies especially on seasonal or monthly scales. High aerosol loadings and their AACs would be observed during the episodes, which lead to relatively higher frequency at the larger AACs. As shown in Fig. 5c, frequencies of values exceeding $65 \mathrm{M} \mathrm{m}^{-1}$ were larger in fall compared to those in other seasons in 2012. Frequencies of the values larger than $55 \mathrm{M} \mathrm{m}^{-1}$ were higher in winter compared to those in other seasons in 2013. In 2012, the frequency of the AAC ranging from 120 to $140 \mathrm{Mm}^{-1}$ in summer was larger $(0.94 \%)$ than that in spring $(0.65 \%)$ and winter $(0.58 \%)$ due to the biomass burning in northwestern regions of Nanjing (Zhuang et al., 2014b). Over all, frequencies of the AAC in 2013 show much more seasonality compared to 2012. Large differences in the frequency distribution between 2012 and 2013 are mainly found in summer and winter.

\subsection{Periodic variation of the aerosol absorption coefficient}

In addition to diurnal cycles, the AAC might have other periodicities during the study period in Nanjing. Thus, Morlet wavelet is employed based on daily mean AAC values at $532 \mathrm{~nm}$ corrected by SC2006. Figure 6 shows the wavelet power spectrum (Fig. 6a) and wavelet real part spectrum (Fig. 6b) of $532 \mathrm{~nm}$ AAC. Cycles of 4-8 days and 9-17 days which are mostly statistically significant at the confidence level of $95 \%$ dominate the local power spectrum, implying that variations of the AAC in the urban area of Nanjing could also be affected by synoptic-scale (weekly) weather systems and quasi-2-week-scale systems to some extent. The oscillations of the AAC on the synoptic scale are found in the period from late fall to early winter due to the quick and vigorous weather change; and quasi-2-week-scale oscillations of the $\mathrm{AAC}$ are mainly in winter. Similar to the AAC, visibility in Nanjing also has synoptic scale and quasi-2-week-scale periodic variations as indicated in Deng et al. (2011), who suggested that the quasi-2-week oscillation might be a regional rather than local phenomenon in China, even in east Asia. 


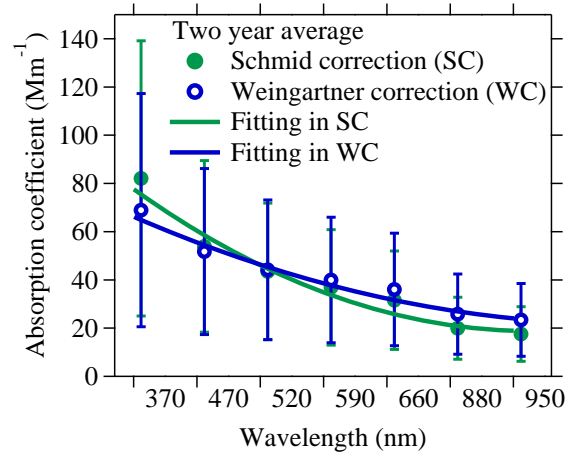

(a)

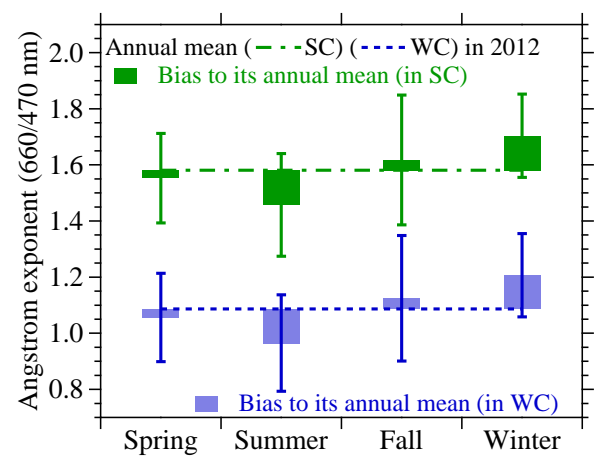

(b)

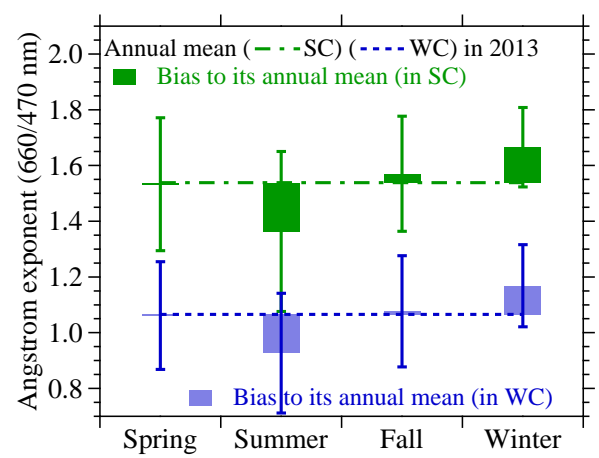

(c)

Figure 7. Dependence of the aerosol absorption coefficient corrected by WC2003 (blue) and SC2006 (green) on the wavelength in the urban area of Nanjing during the period from 2012 to 2013 (a). Annual (dash lines) and seasonal (bars with error bar) absorption Ångström exponents at 660/470 nm from WC2003 (light blue) and SC2006 (green) both in 2012 (b) and 2013 (c).

\subsection{Varied with wavelength of the aerosol absorption coefficient}

In the previous sections, single-wavelength AAC (at $532 \mathrm{~nm}$ ) is discussed as the AAC distribution and seasonal variation are similar among different wavelengths. In this section, we further examine wavelength-dependent AACs as well as AAEs at $660 / 470 \mathrm{~nm}$ corrected by WC2003 and SC2006 (Fig. 7). AACs from both WC2003 and SC2006 decrease with increasing wavelength (Fig. 7a). Although the AAC at $532 \mathrm{~nm}$ from WC2003 is close to that from SC2006, substantial differences exist at other wavelengths. WC2003-AACs are smaller than SC2006-AACs at shorter wavelengths (370 and $470 \mathrm{~nm}$ ) but are larger than SC2006-ACCs in longer wavelengths (from 590 to $950 \mathrm{~nm}$ ). The averaged AACs range from 23.40 (at $950 \mathrm{~nm}$ ) to $68.89 \mathrm{Mm}^{-1}$ (at $370 \mathrm{~nm}$ ), based on WC2003 and range from 17.56 (at $950 \mathrm{~nm}$ ) to $82.07 \mathrm{Mm}^{-1}$ (at $370 \mathrm{~nm}$ ) based on SC2006. Different correction methods on scattering-effect $C$ between WC2003 and SC2006 result in different variations of AAC with wavelengths because $C$ in WC2003 is independent of wavelength, and subsequently might lead to considerably different AAEs between these corrections (Fig. 7b and c). Both Fig. 7b and c show that AAE at $660 / 470 \mathrm{~nm}$ from SC2006 is much larger than that from WC2003, although they have similar seasonality. Annual mean 660/470 nm AAEs in 2012 and 2013 are 1.58 and 1.54 from SC2006, and 1.09 and 1.07 from WC2003. AAE from SC2006 is about 1.5 times that from WC2003. Furthermore, AAE has strong seasonality; it is high in winter and low in summer, implying that absorbing aerosols in summer have larger sizes possibly caused by large relative humidity $(\mathrm{RH})$. Seasonal variations of AAE from AE-31 are similar to those from CE-318 compared with those in Zhuang et al. (2014a), who reported annual mean AAE of the column aerosols from CE-318 of 1.44 at the site, thus suggesting that the scattering correction method by Schmid et al. (2006) was more reasonable than that by Weingartner et al. (2003).

Table 1 summarizes the optical properties of absorbing aerosols from AE-31 based on IDC, WC2003, and SC2006. Two-year averaged values of AAC at $532 \mathrm{~nm}$ corrected by these three methods are 44.38, 43.38, and $41.93 \mathrm{Mm}^{-1}$, respectively, in the urban area of Nanjing. $660 / 470 \mathrm{~nm}$ AAE corrected by WC2003 and SC2006 are $1.08 \pm 0.20$ and $1.56 \pm 0.23$, respectively. Annual mean AAC averaged from all wavelengths is $40.78 \mathrm{M} \mathrm{m}^{-1}$ (SC2006) and $41.41 \mathrm{Mm}^{-1}$ (WC2003), while it is $41.47 \mathrm{Mm}^{-1}$ (SC2006) and $\sim 42.97 \mathrm{M} \mathrm{m}^{-1}$ (WC2006), averaged from visible wavelengths. The interannual difference suggests that the AAC is smaller in 2012 than in 2013, while AAE is larger in 2012 than in 2013. The scattering correction of Weingartner et al. (2003) is different from that of Schmid et al. (2006), which would result in large variances of the AAC at shorter $(<520 \mathrm{~nm})$ or longer $(>590 \mathrm{~nm})$ wavelengths, causing a large difference of AAE between the two methods. However, AACs at $532 \mathrm{~nm}$ or averaged from all wavelengths from WC2003 and SC2006 are close to each other. Many studies on aerosol optical properties have been carried out by model simulations and observations. Most of them focused on the optical depth and single-scattering albedo of column (from surface to the top of the atmosphere) aerosols (Zhuang et al., 2014a), few focused on the aerosol absorption coefficient, and even fewer focused on the AAC in urban areas of YRD. Annual AAE at $660 / 470 \mathrm{~nm}$ corrected 
Table 1. Statistical values of annual aerosol absorption coefficient $\left(\mathrm{Mm}^{-1}\right)$ and absorption Ångström exponent in the urban area of Nanjing.

\begin{tabular}{|c|c|c|c|c|c|c|c|c|c|}
\hline \multirow[t]{2}{*}{ Year } & \multirow[t]{2}{*}{ Schemes } & \multicolumn{2}{|c|}{ All-wave AAC } & \multicolumn{2}{|c|}{ Visible-wave AAC } & \multicolumn{2}{|c|}{$532 \mathrm{~nm}$ AAC } & \multicolumn{2}{|c|}{$\operatorname{AAE}(660 / 470 \mathrm{~nm})$} \\
\hline & & Average & SD & Average & SD & Average & SD & Average & SD \\
\hline \multirow[t]{3}{*}{2012} & IDC & l & l & 1 & I & 42.99 & 26.55 & 1 & I \\
\hline & SC2006 & 39.70 & 35.26 & 40.34 & 27.10 & 41.02 & 25.70 & 1.58 & 0.20 \\
\hline & WC2003 & 40.48 & 31.26 & 41.97 & 27.29 & 42.44 & 26.59 & 1.09 & 0.20 \\
\hline \multirow[t]{3}{*}{2013} & IDC & I & l & l & I & 45.81 & 30.22 & I & I \\
\hline & SC2006 & 41.91 & 38.64 & 42.66 & 30.61 & 42.87 & 29.14 & 1.54 & 0.25 \\
\hline & WC2003 & 42.39 & 34.41 & 43.99 & 30.79 & 44.34 & 30.15 & 1.07 & 0.21 \\
\hline \multirow[t]{3}{*}{ 2-year period } & IDC & l & I & l & l & 44.38 & 28.45 & I & I \\
\hline & SC2006 & 40.78 & 36.97 & 41.47 & 28.89 & 41.93 & 27.47 & 1.56 & 0.23 \\
\hline & WC2003 & 41.41 & 32.86 & 42.97 & 29.08 & 43.38 & 28.41 & 1.08 & 0.20 \\
\hline
\end{tabular}

IDC: the coefficients from the indirect correction. SC2006: the coefficients corrected by Schmid et al. (2006). WC2003: the coefficients corrected by Weingartner et al. (2003). AAC: aerosol absorption coefficient. AAE: absorption Ångström exponent. SD: standard deviation.

by SC2006 agrees well with that observed by CE-318 at the site. Xu et al. (2004) pointed out that the AAC at $565 \mathrm{~nm}$ was $6 \pm 11 \mathrm{Mm}^{-1}$ in the Gobi Desert (Yulin) in China in 1999. In Beijing, the capital of China, annual AAC at $532 \mathrm{~nm}$ was about $17.54 \pm 13.44 \mathrm{Mm}^{-1}$ at a rural site (Shangdianzi: SDZ) in 2003 and 2004 (Yan et al., 2008), while it was about $45 \pm 39 \mathrm{Mm}^{-1}$ at an urban site from 2005 to 2006 (He et al., 2009). The AAC at $532 \mathrm{~nm}$ at a rural site of YRD (Lin'an) was about $44.3 \pm 19.7 \mathrm{Mm}^{-1}$ in 2004 (Yan, 2006). In the semiarid area of northeast China (Tongyu), the AAC at $520 \mathrm{~nm}$ was only about $7.28 \pm 5.87 \mathrm{Mm}^{-1}$ from 2010 to 2011 (Wu et al., 2012). In Pearl River Delta (PRD) of China, annual AAC at $532 \mathrm{~nm}$ was as large as $82 \pm 23 \mathrm{Mm}^{-1}$ at urban areas from 2004 to 2007 (Wu et al., 2009). The magnitude of the annual AAC in the urban area of Nanjing, to some extent, is comparable to that in other Chinese urban or rural sites. It is much lower than in PRD but higher than in non-urban sites of north China (Shangdianzi, Tongyu, and Yulin). In YRD, annual AAC in the urban area of Nanjing is as large as in rural areas (Lin'an), which is similar to the BC concentrations there (Zhuang et al., 2014b).

\subsection{Aerosol absorption coefficient in different wind directions}

In addition to local emissions, the meteorological factors such as the prevailing wind could also affect the AAC and AAE in the urban area of Nanjing. Backward trajectory analysis shown in Fig. 8a and b indicates that Nanjing could be affected by local air flow and long-distance air flows mostly from northwestern, northern, eastern, southeastern, and southern directions both in 2012 and 2013, implying that the prevailing winds might have weaker interannual variations than the aerosols. Air flows from a northern direction account for about half of the totals while the local air flow and the flows from the oceans account for about 13, 19, and $15 \%$, respectively. Frequencies of air flows from south and northwest China are relatively smaller. The rose plot of near-surface wind around the site $\left(32^{\circ} \mathrm{N}, 118.76^{\circ} \mathrm{E} ; 8 \mathrm{~m}\right.$ tall) during the entire study period (Fig. 8c) suggests that the distributions of the near-surface wind directions somewhat agree with those from the backward trajectory analysis. However, the winds near the surface flow from the southeast to the east more frequently, accounting for more than $35 \%$ of the totals. The wind from south to west occurs the least (Fig. 8c). The wind speed is mostly concentrated in the values from 2 to $6 \mathrm{~m} \mathrm{~s}^{-1}$ in Nanjing during the period.

As mentioned, wind direction shifting over different seasons might be another important factor in determining the aerosol AAC and AAE. Zhuang et al. (2014b) indicated that high BC loadings in fall and summer of 2012 were observed at the site when winds were from northeastern and northwestern directions, in which air masses might be highly polluted, thus leading to considerably large AAC. Figure 9 presents the AAC at $532 \mathrm{~nm}$ and $\mathrm{AAE}$ at $660 / 470 \mathrm{~nm}$ corrected by SC2006 associated with different clusters (shown in Fig. 8) in the urban area of Nanjing both in 2012 and 2013. Considerable air pollutants are derived from local and subregional emissions as presented in cluster 6 (Figs. 9a and 8a) in 2012 and in cluster 3 (Figs. 9b and 8b) in 2013, with averaged values of 56.13 and $65.38 \mathrm{M} \mathrm{m}^{-1}$, respectively. Air masses from the oceans and south China (or South China Sea) (cluster 7, 8, and 9 in Fig. 8a and b) were relatively clean, leading to smaller AACs in Nanjing (Fig. 9a and b), with averaged values of $33.28 \mathrm{M} \mathrm{m}^{-1}$ in 2012 and $30.1 \mathrm{M} \mathrm{m}^{-1}$ in 2013. The air masses from the remote sites (cluster 2, 3, and 4 in 2012 in Fig. 8a and cluster 1, 4, and 5 in 2013 in Fig. 8b) could also bring the clean air and then might result in relatively low levels of AACs in Nanjing. Previous analysis indicates that prevailing winds have weak interannual variations. Therefore, substantial differences (about $15 \mathrm{Mm}^{-1}$ ) between the AAC from cluster 3 (or cluster 5) in 2012 and cluster 2 (or cluster 6) in 2013 might mostly result from the regional pollution 


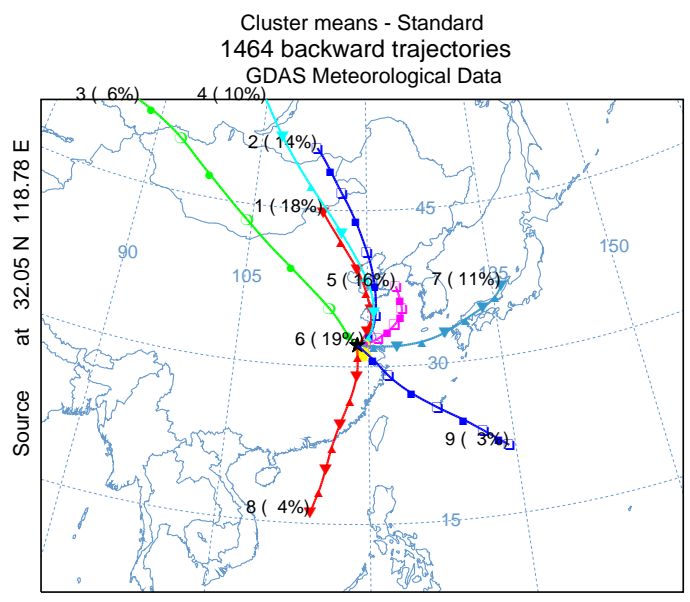

(a)

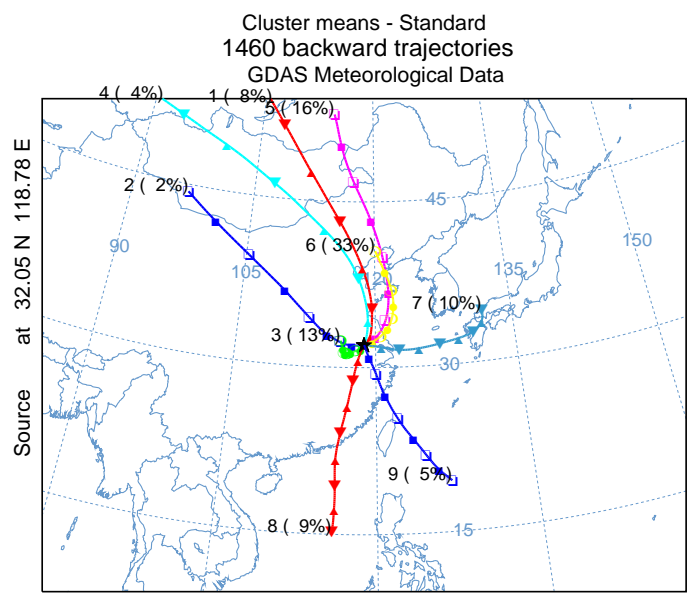

(b)

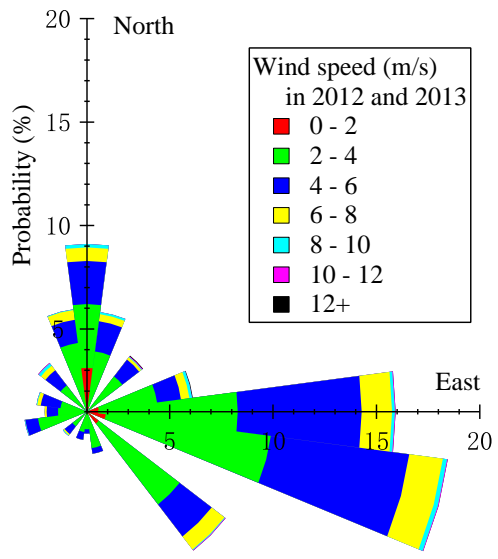

(c)

Figure 8. Clusters of $96 \mathrm{~h}$ back trajectories arriving at the study site at $100 \mathrm{~m}$ in 2012 (a) and 2013 (b) simulated by the HYSPLIT model and the probability distributions of $6 \mathrm{~h}$ interval near-surface wind speed in different wind directions in Nanjing (c).

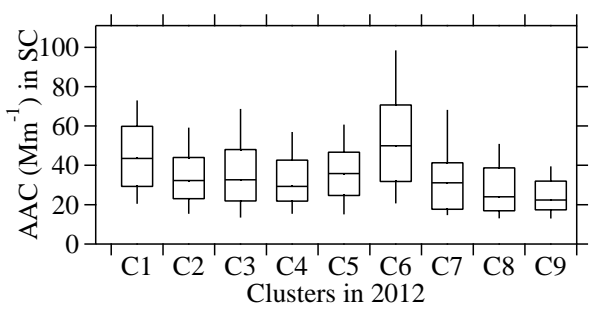

(a)

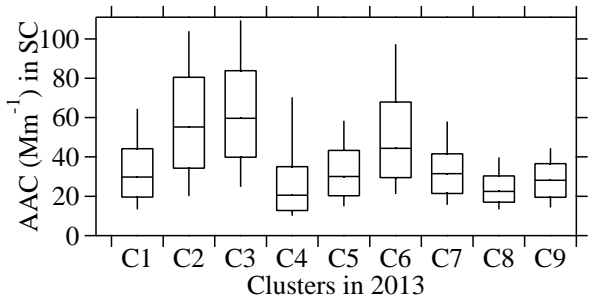

(b)

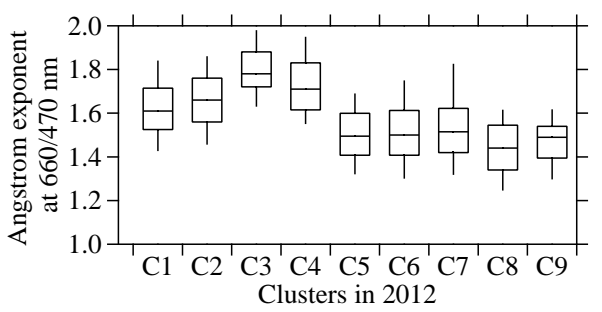

(c)

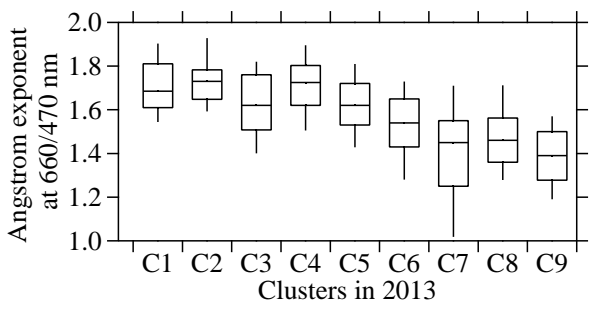

(d)

Figure 9. The 10, 25, 50, 75, and $90 \%$ percentile values of the aerosol absorption coefficient (a, b) and absorption Ångström exponent (c, d) in each cluster of back trajectories in 2012 (Fig. 8a) and 2013 (Fig. 8b).

episodes in north China in 2013. In addition to the AAC, the AAE is also somewhat affected by different air flows. Figure $9 \mathrm{c}$ and $\mathrm{d}$ suggest that AAE in the urban area of Nanjing is relatively small when the air masses come from the oceans (cluster 7 and 9) possibly due to the effects of moisture, while it is larger when the flows are from the areas of higher latitudes. Local AAEs are 1.52 (in cluster 6 in Fig. 9c) in 2012 and 1.62 (in cluster 3 in Fig. 9d) in 2013, which are close to the annual mean value of 1.56 . 


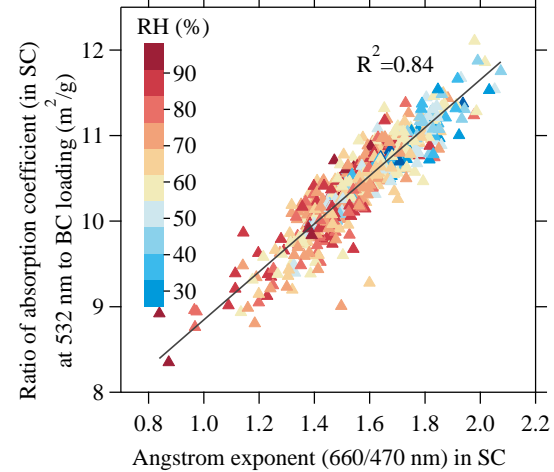

(a)

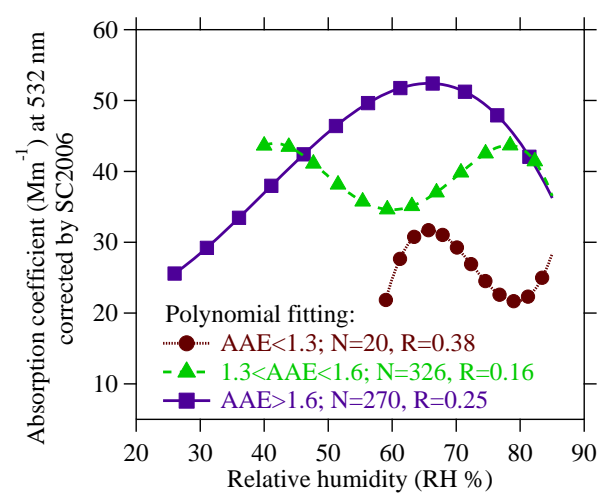

(b)

Figure 10. Relationships between the aerosol mass (or specific) absorption coefficient $\left(\mathrm{m}^{2} \mathrm{~g}^{-1}\right)$ and its Ångström exponent (a, scatter plots) and the effects of relative humidity on the aerosol absorption coefficient (a, in color) and (b) in different absorption Ångström exponent levels.

\subsection{Relationship between aerosol absorption coefficient and its absorption Ångström exponent}

Aerosol absorption coefficient is directly determined by the loadings of absorbing aerosols. Additionally, both the aerosol size distribution and relative humidity $(\mathrm{RH})$, especially the former, are closely related to the variation in the AAC values. Figure 10 shows the relationships among the AAC at $532 \mathrm{~nm}$ corrected by SC2006, AAE at $660 / 470 \mathrm{~nm}$ corrected by SC2006, and RH. It suggests that changes in aerosol mass (or specific) absorption coefficients (MAC for short, defined as ratios of $\mathrm{AAC}$ to $\mathrm{BC}$ loading, in $\mathrm{m}^{2} \mathrm{~g}^{-1}$ ) at $532 \mathrm{~nm}$ are closely relative to the variations of AAE. High levels of MAC mostly occur in the ranges with large AAE, implying that absorbing aerosols with smaller sizes might absorb more solar radiation because the fine particles have much larger specific surface areas compared to coarse ones. The linear correlation coefficient between MAC and AAE exceeded 0.92 in the urban area of Nanjing during the study period (Fig. 10a). Changes in AAE are somewhat influenced by the variations of RH. Fig. 10a also indicates that large AAEs are mostly found when the RH is low and vice versa. Generally, moist air is in favor of hygroscopic growth of the aerosols, thus resulting in smaller AAE (corresponding to large size of the aerosols). These results could further explain why AAE in the urban area of Nanjing is relatively small when the air masses come from the oceans as discussed in the previous section (Figs. 8 and 9). In addition to $\mathrm{AAE}$, the $\mathrm{AAC}$ is also affected by RH, as shown in Fig. 10b for the AAC$\mathrm{RH}$ relationship in different AAE levels. A large AAC occurs in the range with large AAE, while coarser aerosols (AAE $<1.3$ ) could only be found under the condition of large RH. Changes in the AAC with RH are different within different bins of AAE. Polynomial fitting between the AAC and $\mathrm{RH}$ indicates that the peaks of the AAC mainly concentrate at $\mathrm{RH}$, being $65 \%$ for the finer (AAE > 1.6) absorbing aerosols (unimodal), while for coarser ones, quasi-bimodal distribution of the AAC is found. High levels of AAC within the ranges of AAE from 1.3 to 1.6 mostly occur at 40 and $80 \%$. Large AACs within the ranges of AAE below 1.3 are mostly found in the value of 65 and $85 \%$. Polynomial correlation coefficients of these three fittings are $0.25,0.16$, and 0.38 , respectively, which is statistically significant at the confident levels of 99,99 , and $90 \%$.

\subsection{Aerosol absorption coefficient during pollution episodes}

The previous analysis indicates that extremely high aerosols were observed from serious pollution episodes, which might affect the temporal and frequency distributions of the AAC in the urban area of Nanjing. The diurnal variation of $\mathrm{BC}$ in the period from 1 to 15 June 2012 was altered significantly from its normal distribution (Zhuang et al., 2014b), as was the AAC in this period, as expected. The mean of the AAC at $532 \mathrm{~nm}$ from January 2012 to December 2013 shown in Table 1 is about $43 \mathrm{Mm}^{-1}$. However, the daily mean AACs that far outstrip the value $90 \mathrm{Mm}^{-1}$, which is $\sim 2$ times of the annual mean, are found frequently, especially in March, June, and November of 2012 and in January, November, and December of 2013 (Fig. 11). The largest values of the daily AAC at 532 corrected by SC2006 in these months all exceeded $100 \mathrm{Mm}^{-1}$, especially on 10 June 2012 and 4 December 2013 when AACs were as large as 147.19 and $149.38 \mathrm{M} \mathrm{m}^{-1}$, respectively. The high AAC in June 2012 mainly result from biomass burning in the northwestern region of Nanjing (counted a part of local pollution in cluster 6 of Fig. 8a), as discussed in Zhuang et al. (2014b). The magnitude and distribution of AOD from satellite (MODIS) retrievals (not shown) suggest that the high aerosol loadings or absorption coefficients during the periods from 9 to 13 January 2013 and from 1 to 8 December 2013 might be possibly caused by large-scale regional pollution over east to north China (Nanjing is included). The reasons leading to high aerosol pollution in Nanjing during the sampling period 


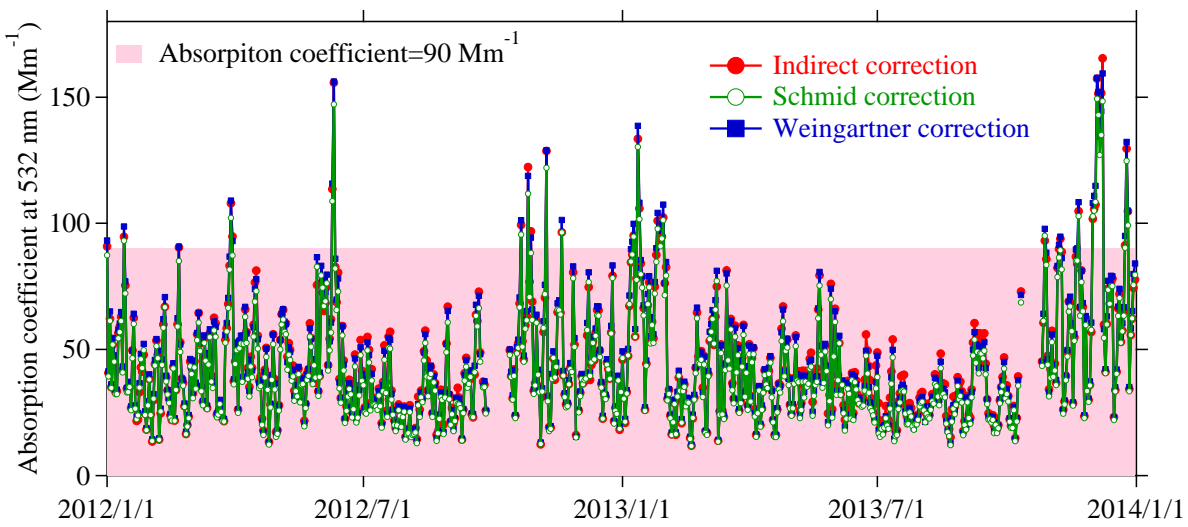

Figure 11. Time series of daily mean aerosol absorption coefficient at $532 \mathrm{~nm}$ corrected by IDC (red), WC2003 (blue) and SC2006 (green) in the period from 2012 to 2013 .

would be analyzed in detailed in further studies, as would the characteristics of the AAC and $\mathrm{AAE}$ in pollution episodes.

\section{Conclusions}

In this study, the near-surface aerosol absorption coefficient (AAC) and Ångström exponent (AAE) in the urban area of Nanjing in 2012 and 2013 are investigated based on the measurements from the 7-channel Aethalometer (model AE-31, Magee Scientific, USA). As suggested by Collaud Coen et al. (2010), Weingartner et al. (2003) (WC2003 for short), and Schmid et al. (2006) (SC2006 for short), corrections are used to assess the AAE at $660 / 470 \mathrm{~nm}$ and wavelength-dependent AAC. The indirect correction (IDC) is also used to estimate the $532 \mathrm{~nm}$ AAC based on the observed conversion factor in Nanjing. Analysis of the AAC is focused on at wavelength $532 \mathrm{~nm}$ to facilitate the comparisons between the direct and indirect correction of AACs, as the temporal variation and frequency distribution of ACC at each wavelength are similar to those at $532 \mathrm{~nm}$.

The direct and indirect corrections closely agree in terms of the temporal variation and magnitude of the AAC at $532 \mathrm{~nm}$ in the entire study period except in spring and summer, possibly due to the strong shadowing effect in these seasons. The AAC at $532 \mathrm{~nm}$ corrected by IDC is the largest, followed by that from WC2003 and SC2006. The mean AAC at $532 \mathrm{~nm}$ averaged from these three corrections is about $43.23 \pm 28.13 \mathrm{Mm}^{-1}$ in the urban area of Nanjing, with substantial seasonal and diurnal variations. Higher AACs often occur in cold seasons (at rush hour), while lower ones occur in summer (in afternoon). A small AAC in the summer (in the afternoon) is partially due to large scavenging efficiency and smaller emission rates of the aerosols (the well-developed boundary layers). The AAC in the urban area of Nanjing is much lower than that in Pearl River Delta but higher than that at non-urban sites of north China. Within YRD, the annual AAC in the urban area of Nanjing is as large as that in rural areas (Lin'an). Wavelet analysis suggests that variations of the AAC in the urban area of Nanjing might have cycles of 4-8 days and 9-17 days due to the affection of synoptic scale (weekly) weather systems and quasi-2-week-scale systems. AACs follow a typical log-normal pattern in terms of the frequency distribution. For the AAC at $532 \mathrm{~nm}$, the range from 15 to $65 \mathrm{M} \mathrm{m}^{-1}$ dominates, accounting for more than $72 \%$ of the total data samples in the entire study period. The maximum frequencies of about $10-11 \%$ occur in the range of 25 to $30 \mathrm{Mm}^{-1}$. Both diurnal variations and frequency distributions of the AAC show more evident seasonality in 2013 than in 2012, possibly because of the influences of the pollution episodes.

The AAC in the urban area of Nanjing has been affected by serious pollution episodes locally and regionally; thus much enhanced AACs have been observed frequently. AACs are expected to be small in summer due to low BC concentrations at that time. However, AACs were substantially large (exceeding $50 \mathrm{Mm}^{-1}$ ) in June 2012 due to a high intensity of biomass burning around Nanjing during 1-15 June 2012. Extremely high AACs in winter in 2013 might be caused by large-scale regional pollution over east to north China. Hence, the AAC diurnal cycle, frequency, and its seasonal variations were altered. High AACs occurred at midnight during the period 1-15 June 2012, instead of in the morning as usual. The frequency of AAC followed a quasi-bimodal distribution in winter in 2013, and its values in the AAC range that are larger than $55 \mathrm{Mm}^{-1}$ were higher compared to other seasons in 2013.

The AAC at the site generally decreases with increasing wavelength. Although the AAC at $532 \mathrm{~nm}$ from WC2003 is close to the one from SC2006, its decline rate is smaller than from SC2006, because the scattering correction $C$ from WC2003 is independent of wavelength. Thus, AAE at $660 / 470 \mathrm{~nm}$ from SC2006 (i.e., 1.56) is much larger than that from WC2003 (i.e., 1.08). The scattering correction by Schmid et al. (2006) appears to be more reasonable than the 
correction by Weingartner et al. (2003), compared to the column AAE at $675 / 440 \mathrm{~nm}$ by CE-318 at the site. AAE also has strong seasonality; it is high in winter and low in summer, possibly related to the variation in relative humidity $(\mathrm{RH})$ (Zhuang et al., 2014a).

Wind-direction shifting over different seasons might be another factor controlling the aerosol AAC and AAE. Backward trajectories indicate that Nanjing could be affected by local air flow (13-19\%) and long-distance air flows mostly from northwestern, northern (>50\%), eastern, southeastern, and southern directions. Considerable air pollution in the urban area of Nanjing is due to local and subregional emissions. Air masses from the oceans and remote areas are relatively clean with low AACs. During the pollution episodes in north China in 2013, a large number of aerosols were transported to Nanjing, greatly enhancing the AAC at the site. The $\mathrm{AAE}$ at the site is usually low when the air masses come from the oceans, while it is high when the air flows from higher latitudes.

The AAC generally increases with increasing AAE under the condition of fixed aerosol loadings in the urban area of Nanjing. The linear correlation coefficient between MAC at $532 \mathrm{~nm}$ and the AAC exceeds 0.92 during the entire study period. High levels of MAC mostly occur in the ranges with large AAE because the fine particles have a much larger specific surface area compared to coarse ones. Changes in the $\mathrm{AAE}$ and $\mathrm{AAC}$ are somewhat influenced by the variations of $\mathrm{RH}$. Large AAEs are mostly found when the RH is low and vice versa. Changes in the AAC with $\mathrm{RH}$ are different within different bins of AAE. Unimodal and quasi-bimodal distributions of the AAC vary with RH for finer (AAE > 1.6) and coarser (AAE < 1.6) absorbing aerosols, respectively. The peak AAC mainly concentrates at $\mathrm{RH}=65 \%$ for the aerosols with $\mathrm{AAE}<1.6$. For the aerosols with $1.3<\mathrm{AAE}<1.6$, the maximum AACs occur at RHs of around 40 and $80 \%$, while for $\mathrm{AAE}<1.3$, AACs peak at RHs of around 65 and $85 \%$.

Acknowledgements. This work was supported by the National Key Basic Research Development Program of China (2014CB441203 and 2011CB403406), the Young Scientists Fund of the National Natural Science Foundation of China (41205111), the New Teachers' Fund for Doctor Stations, Ministry of Education (20120091120031), the Fundamental Research Funds for the Central Universities (20620140744), FP7 project: REQUA (PIRSES-GA-2013-612671), and a project funded by the Priority Academic Program Development of the Jiangsu Higher Education Institutions (PAPD). The authors would like to thank all members in the AERC of Nanjing University for maintaining instruments. The HYSPLIT model was supplied by NOAA: http://ready.arl.noaa.gov/HYSPLIT_traj.php.

Edited by: S. Gong

\section{References}

Ångström, A.: On the atmospheric transmission of sun radiation and on dust in the air, Geogr. Ann., 11, 156-166, 1929.

Arnott, W. P., Hamasha, K., Moosmuller, H., Sheridan, P. J., and Ogren, J. A.: Towards aerosol light-absorption measurements with a 7-wavelength aethalometer: evaluation with a photoacoustic instrument and 3-wavelength nephelometer, Aerosol Sci. Tech., 39, 17-29, doi:10.1080/027868290901972, 2005.

Bai, H. T., Chen, Y. H., Wang, H. Q., Zhang, Q., Guo, N., Wang, S., Pan, H., and Zhang, P.: Seasonal variation of aerosol optical properties at AERONET of the semi-arid region in Loess Plateau, Arid Land Geogr., 34, 1-8, 2011.

Bellouin, N., Boucher, O., Tanré, D., and Dubovik, O.: Aerosol absorption over the clear-sky oceans deduced from POLDER1 and AERONET observations, Geophys. Res. Lett., 30, 1748, doi:10.1029/2003GL017121, 2003.

Cai, H. K., Zhou, R. J., Fu, Y. F., Zheng, Y. Y., and Wang, Y. J.: Cloud-aerosol lidar with or thogonal polarization detection of aerosol optical properties after a crop burning case, Clim. Environ. Res., 16, 469-478, 2011.

Collaud Coen, M., Weingartner, E., Apituley, A., Ceburnis, D., Fierz-Schmidhauser, R., Flentje, H., Henzing, J. S., Jennings, S. G., Moerman, M., Petzold, A., Schmid, O., and Baltensperger, U.: Minimizing light absorption measurement artifacts of the Aethalometer: evaluation of five correction algorithms, Atmos. Meas. Tech., 3, 457-474, doi:10.5194/amt-3-457-2010, 2010.

Deng, J. J., Wang, T. J., Jiang, Z. Q., Xie, M., Zhang, R. J., Huang, X. X., and Zhu, J. L.: Characterization of visibility and its affecting factors over Nanjing, China, Atmos. Res., 101, 681-691, doi:10.1016/j.atmosres.2011.04.016, 2011.

Forster, P., Ramaswamy, V., Artaxo, P., Berntsen, T., Betts, R., Fahey, D. W., Haywood, J., Lean, J., Lowe, D. C., Myhre, G., Nganga, J., Prinn, R., Raga, G., Schulz, M., and Van Dorland, R.: Changes in atmospheric constituents and in radiative forcing, in: Climate Change 2007: The Physical Science Basis. Contribution of Working Group I to the Fourth Assessment Report of the Intergovernmental Panel on Climate Change, edited by: Solomon, S., Qin, D., Manning, M., Chen, Z., Marquis, M., Averyt, K. B., Tignor, M., and Miller, H. L., Cambridge Univ. Press, Cambridge, UK, 129-234, 2007.

Hansen, A. D. A., Rosen, H., and Novakov, T.: The aethalometer: an instrument for the real time measurements of optical absorption by aerosol particles, Sci. Total Environ., 36, 191-196, 1984.

He, X., Li, C. C., Lau, A. K. H., Deng, Z. Z., Mao, J. T., Wang, M. H., and Liu, X. Y.: An intensive study of aerosol optical properties in Beijing urban area, Atmos. Chem. Phys., 9, 8903-8915, doi:10.5194/acp-9-8903-2009, 2009.

Holler, R., Ito, K., Tohno, S., and Kasahara, M.: Wavelengthdependent aerosol single scattering albedo: measurements and model calculations for a coastal site near the sea of Japan during ACE-Asia, J. Geophys. Res., 108, 8648, doi:10.1029/2002JD003250, 2003.

Jacobson, M. Z.: Control of fossil-fuel particulate black carbon and organic matter, possibly the most effective method of slowing global warming, J. Geophys. Res., 107, 4410, doi:10.1029/2001JD001376, 2002.

Kiehl, J. T. and Briegleb, B. P.: The relative roles of sulfate aerosols and greenhouse gases in climate forcing, Science, 260, 311-314, 1993. 
Li, Z. Q., Lee, K. H., Wang, Y. S., Xin, J. Y., and Hao, W. M.: First observation-based estimates of cloud-free aerosol radiative forcing across China, J. Geophys. Res., 115, D00K18, doi:10.1029/2009JD013306, 2010.

Liao, H. and Seinfeld, J. H.: Global impacts of gas-phase chemistryaerosol interactions on direct radiative forcing by anthropogenic aerosols and ozone, J. Geophys. Res., 110, D18208, doi:10.1029/2005JD005907, 2005.

Menon, S., Hansen, J., Nazarenko, L., and Luo, Y. F.: Climate effects of black carbon aerosols in China and India, Science, 297, 2250-2253, doi:10.1126/science.1075159, 2002.

Penner, J. E., Andreae, M., Annegarn, H., Barrie, L., Feichter, J., Hegg, D., Jayaraman, A., Leaitch, R., Murphy, D., Nganga, J., and Pitari, G.: Aerosols, their direct and indirect effects, in: Climate Change 2001: The Scientific Basis. Contribution of Working Group I to the Third Assessment Report of the Intergovernmental Panel on Climate Change, edited by: Houghton, J. T., Ding, Y., Griggs, D. J., Noguer, M., van der Linden, P. J., Dai, X., Maskell, K., and Johnson, C. A., Cambridge University Press, Cambridge, UK and New York, NY, USA, 289-348, 2001.

Petzold, A., Kopp, C., and Niessner, R.: The dependence of the specific attenuation cross-section on black carbon mass fraction and particle size, Atmos. Environ., 31, 661-672, 1997.

Schmid, O., Artaxo, P., Arnott, W. P., Chand, D., Gatti, L. V., Frank, G. P., Hoffer, A., Schnaiter, M., and Andreae, M. O.: Spectral light absorption by ambient aerosols influenced by biomass burning in the Amazon Basin. I: Comparison a nd field calibration of absorption measurement techniques, Atmos. Chem. Phys., 6, 3443-3462, doi:10.5194/acp-6-3443-2006, 2006.

Streets, D. G., Gupta, S., Waldhoff, S. T., Wang, M. Q., Bond, T. C., and Bo, Y. Y.: Black carbon emissions in China, Atmos. Environ., 35, 4281-4296, doi:10.1016/S1352-2310(01)00179-0, 2001.

Virkkula, A., Makela, T., Hillamo, R., Yli-Tuomi, T., Hirsikko, A., Hameri, K., and Koponen, I. K.: A simple procedure for correcting loading effects of aethalometer data, J. Air Waste Manage., 57, 1214-1222, doi:10.3155/1047-3289.57.10.1214, 2007.

Wang, Y., Che, H. Z., Ma, J. Z., Wang, Q., Shi, G. Y., Chen, H. B., Goloub, P., and Hao, X. J.: Aerosol radiative forcing under clear, hazy, foggy, and dusty weather conditions over Beijing, China, Geophys. Res. Lett., 36, L06804, doi:10.1029/2009GL037181, 2009.

Weingartner, E., Saathoff, H., Schnaiter, M., Streit, N., Bitnar, B., and Baltensperger, U.: Absorption of light by soot particles: determination of the absorption coefficient by means of aethalometers, J. Aerosol Sci., 34, 1445-1463, doi:10.1016/S00218502(03)00359-8, 2003.

Wu, D., Mao, J. T., Deng, X. J., Tie, X. X., Zhang, Y. H., Zeng, L. M., Li, F., Tan, H. B., Bi, X. Y., Huang, X. Y., Chen, J., and Deng, T.: Black carbon aerosols and their radiative properties in the Pearl River Delta region, Sci. China Ser. D, 52, 1152-1163, doi:10.1007/s11430-009-0115-y, 2009.

Wu, D., Wu, C., Liao, B., Chen, H., Wu, M., Li, F., Tan, H., Deng, T., Li, H., Jiang, D., and Yu, J. Z.: Black carbon over the South China Sea and in various continental locations in South China, Atmos. Chem. Phys., 13, 12257-12270, doi:10.5194/acp13-12257-2013, 2013.
Wu, Y. F., Zhang, R. J., Pu, Y. F., Zhang, L. M., Ho, K. F., and Fu, C. B.: Aerosol optical properties observed at a semi-arid rural site in northeastern China, Aerosol Air Qual. Res., 12, 503-514, 2012.

Xia, X. A., Li, Z. Q., Holben, B., Wang, P., Eck, T., Chen, H. B., Cribb, M., and Zhao, Y. X.: Aerosol optical properties and radiative effects in the Yangtze Delta region of China, J. Geophys. Res., 112, D22S12, doi:10.1029/2007JD008859, 2007.

Xiao, Z. Y., Jiang, H., Chen, J., Wang, B., and Jiang, Z. S.: Monitoring the aerosol optical properties over Hangzhou using remote sensing data, Acta Sci. Circumst., 31, 1758-1767, 2011.

Xu, J., Bergin, M. H., Greenwald, R., Schauer, J. J., Shafer, M. M., Jaffrezo, J. L., and Aymoz, G.: Aerosol chemical, physical, and radiative characteristics near a desert source region of Northwest China during ACE-Asia, J. Geophys. Res., 109, D19S03, doi:10.1029/2003JD004239, 2004.

Yan, P.: Study on the aerosol optical properties in the background regions in the East part of China, PhD Thesis, Peking University, China, 2006.

Yan, P., Tang, J., Huang, J., Mao, J. T., Zhou, X.J., Liu, Q., Wang, Z. F., and Zhou, H. G.: The measurement of aerosol optical properties at a rural site in Northern China, Atmos. Chem. Phys., 8, 2229-2242, doi:10.5194/acp-8-2229-2008, 2008.

Zhang, Q., Streets, D. G., Carmichael, G. R., He, K. B., Huo, H., Kannari, A., Klimont, Z., Park, I. S., Reddy, S., Fu, J. S., Chen, D., Duan, L., Lei, Y., Wang, L. T., and Yao, Z. L.: Asian emissions in 2006 for the NASA INTEX-B mission, Atmos. Chem. Phys., 9, 5131-5153, doi:10.5194/acp-9-5131-2009, 2009.

Zhou, B., Zhang, L., Cao, X. J., Han, X., Zhang, W., and Feng, G. H.: Analyses on atmospheric aerosol optical properties with lidar data in Lanzhou suburb, Plateau Meteorol., 30, 1011-1017, 2011.

Zhu, J., Wang, T., Talbot, R., Mao, H., Hall, C. B., Yang, X., Fu, C., Zhuang, B., Li, S., Han, Y., and Huang, X.: Characteristics of atmospheric Total Gaseous Mercury (TGM) observed in urban Nanjing, China, Atmos. Chem. Phys., 12, 12103-12118, doi:10.5194/acp-12-12103-2012, 2012.

Zhuang, B. L., Li, S., Wang, T. J., Deng, J. J., Xie, M., Yin, C. Q., and Zhu, J. L.: Direct radiative forcing and climate effects of anthropogenic aerosols with different mixing states over China, Atmos. Environ., 79, 349-361, doi:10.1016/j.atmosenv.2013.07.004, 2013a.

Zhuang, B. L., Liu, Q., Wang, T. J., Yin, C. Q., Li, S., Xie, M., Jiang, F., and Mao, H. T.: Investigation on semi-direct and indirect climate effects of fossil fuel black carbon aerosol over China, Theor. Appl. Climatol., 114, 651-672, doi:10.1007/s00704-0130862-8, 2013b.

Zhuang, B. L., Wang, T. J., Li, S., Liu, J., Talbot, R., Mao, H. T., Yang, X. Q., Fu, C. B., Yin, C. Q., Zhu, J. L., Che, H. Z., and Zhang, X. Y.: Optical properties and radiative forcing of urban aerosols in Nanjing, China, Atmos. Environ., 83, 43-52, 2014a.

Zhuang, B. L., Wang, T. J., Liu, J., Li, S., Xie, M., Yang, X. Q., Fu, C. B., Sun, J. N., Yin, C. Q., Liao, J. B., Zhu, J. L., and Zhang, Y.: Continuous measurement of black carbon aerosol in urban Nanjing of Yangtze River Delta, China, Atmos. Environ., 89, 415-424, 2014b. 